\title{
One pathogen two stones: Are Australian tree frog antimicrobial peptides synergistic against human pathogens?
}

\author{
Marc-Antoine Sani ${ }^{1 *}$, Siobhan Carne ${ }^{1}$, Sarah A. Overall ${ }^{1}$, Alexandre Poulhazan ${ }^{1,2}$ and \\ Frances Separovic ${ }^{1, *}$ \\ ${ }^{1}$ School of Chemistry, Bio21 Institute, University of Melbourne, VIC 3010, Australia. \\ ${ }^{2}$ Universite Pierre et Marie Curie (Paris VI), 4 Place Jussieu, 75252 Paris Cedex 5, France
}

Running title: Synergistic interaction between antimicrobial peptides

Key words: antimicrobial peptides, synergy, E. coli, S. aureus, phospholipid membrane, circular dichroism

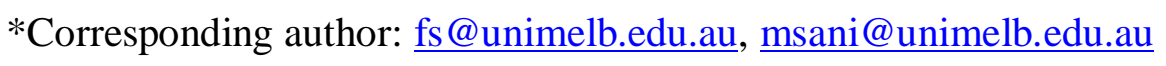




\begin{abstract}
Antimicrobial peptides (AMPs) may act by targeting the lipid membranes and disrupting the bilayer structure. In this study, three AMPs from the skin of Australian tree frogs, aurein 1.2, maculatin 1.1 and caerin 1.1, were investigated against Gram-negative Escherichia coli, Gram-positive Staphylococcus aureus, and vesicles that mimic their lipid compositions. Furthermore, equimolar mixtures of the peptides were tested to identify any synergistic interactions in antimicrobial activity. Minimum inhibition concentration and minimum bactericidal concentration assays showed significant activity against $S$. aureus but not against E. coli. Aurein was the least active while maculatin was the most active peptide and some synergistic effects were observed against $S$. aureus. Circular dichroism experiments showed that, in the presence of phospholipid vesicles, the peptides transitioned from an unstructured to a predominantly helical conformation (> 50\%), with greater helicity for POPG/TOCL compared to POPE/POPG vesicles. The helical content, however, was less in the presence of live E. coli and S. aureus, $25 \%$ and 5\%, respectively. Equimolar concentrations of the peptides did not appear to form greater supramolecular structures. Dye release assays showed that aurein required greater concentration than caerin and maculatin to disrupt the lipid bilayers, and mixtures of the peptides did not cooperate to enhance their lytic activity. Overall, aurein, maculatin and caerin showed moderate synergy in antimicrobial activity against $S$. aureus without becoming more structured or enhancement of their membranedisrupting activity in phospholipid vesicles.
\end{abstract}

\title{
Introduction
}

Living organisms wage permanent warfare against non-symbiotic microbes. To maintain the population of the pathogens under a critical concentration, they can fire the appropriate bullet from a complex innate arsenal. In particular, each organism has evolved a concoction of cationic antimicrobial peptides (AMPs) that defend the host by targeting the prokaryotic lipid membrane, which are mainly negatively charged in contrast to the more neutral eukaryotic membrane. AMPs are seen as a promising direction to generate a new class of antibacterials (or antibiotics) that would not require internalization but instead target the external non stereo-specific lipid membrane thus limiting resistance mechanism. The production of several AMPs by higher organisms in response to a bacterial infection presents the possibility of the existence of synergistic interactions against the pathogen. 
In recent times, antibiotic resistance has had a significant impact on morbidity and mortality in both community and healthcare settings (Apponyi et al. 2004; Hancock and Chapple 1999; Hancock and Lehrer 1998; Nakatsuji and Gallo 2012). The search for new targets and/or agents for effective antimicrobial therapy has long been the focus of much research and multiple factors have been known to contribute to the phenotype and genotype of antibioticresistant bacterial strains (Ambroggio et al. 2004; Pasupuleti et al. 2012). Important differences between antibiotic-resistant and antibiotic-sensitive strains are not only attributed to particular genes (such as $m e c A$ in methicillin resistance), but also the presence of differing methods of pathogenicity and various other virulence factors, such as adhesion molecules, toxins and enzymes which help to confer resistance (Nakatsuji and Gallo 2012). In the search for new lines of antibacterial agents, there are thousands of naturally occurring AMPs. These peptides have been discovered in many living organisms throughout the evolutionary tree (Apponyi et al. 2004). They have a range of activities from bacteriostatic and/or bacteriocidal, microbicidal (i.e., against viral or fungal infections) and cytolytic properties, i.e., anti-inflammatory or cytotoxic activity against cancerous cells (Apponyi et al. 2004; Hancock and Chapple 1999; Hancock and Lehrer 1998; Nakatsuji and Gallo 2012). Therefore, to consider mixing AMPs in order to obtain a synergistically enhanced response against several modes of virulence at once is an interesting prospect. These peptides are the subject of many reviews and studies of their structure and function may lead to design of new lines of antibacterial agents, which use AMPs as their templates or as vehicles to improve drug delivery to target cells (Sani and Separovic 2016).

The structure-function relationship between lipid environments and the activity of AMPs has been investigated through a variety of different model membrane systems (Lee et al. 2016; Nguyen et al. 2011; Salditt et al. 2006; Sani et al. 2013). Lipid characteristics can determine the mode of action of AMPs. These characteristics can include chain length, lipid type, head group, bilayer thickness, curvature and charge (Sani et al. 2012). Lipid systems which mimic eukaryotic or prokaryotic lipid membranes are employed to identify possible mechanisms of action (Sani and Separovic 2016). Specifically, Gram-negative bacteria such as Escherichia coli have an inner and outer membrane with the latter mainly composed of lipopolysaccharides (LPS) and the inner composed of phosphatidylethanolamine (PE) and phosphatidylglycerol (PG) (Sani et al. 2015a). By contrast, Gram-positive bacteria such as Staphylococcus aureus are mostly composed of PG and cardiolipin (CL) (Sani et al. 2013). Mechanistic studies usually performed to study the action of AMPs involve model 
membranes composed of pure or mixed lipid systems (Blazyk et al. 2001; Fernandez et al. 2013a; Fernandez et al. 2012; Fernandez et al. 2013b; Sani et al. 2014; Sani et al. 2015b; Tachi et al. 2002). These liposomal systems usually involve lipids such as negatively charged PG or zwitterionic PE or phosphatidylcholine (PC), which are then extruded in small or large unilamellar vesicles (SUV and LUV, respectively). For example, eukaryotic model systems are represented by lipids such as PC, phosphatidylserine (PS) or PE, usually with a degree of unsaturation, and up to 30 mole\% of cholesterol. Prokaryotic systems may have PE, PG and CL based on species or cell-specific proportion. The drawbacks of such model membrane systems include the failure to reflect lipid heterogeneity, the presence of membrane proteins, negatively charged oligosaccharides, osmolarity, $\mathrm{pH}$ or membrane potential (Sani et al. 2015a). However, a recent NMR study (Laadhari et al. 2016) reports on the interaction with live bacteria of AMPs from Australian tree frogs. Nevertheless, these model membranes are important for mechanistic studies into the structure and function of AMPs.

In the present work, three AMPs from the dermal secretions of Australian tree frogs, namely aurein 1.2 , maculatin 1.1 and caerin 1.1 , were investigated. They are weakly cationic $(+1$ charge at pH 7), amphipathic and are 13, 21 and 25 residues long, respectively. Since their discovery (Apponyi et al. 2004), great effort has been spent on understanding the structureactivity relationship in particular lipid membrane compositions to explain the strain-specific bactericidal concentrations. For instance, aurein acts via a carpet or detergent-like mechanism and is only potent against Gram-positive bacteria while maculatin is a pore-former and can only slightly temper Gram-negatives and has haemolytic activity (Rozek et al. 1998). Caerin is the most efficient against Gram-positives and negatives, but its mode of action, although likely similar to maculatin, has not been as fully characterized. Having another string in the bow is often critical in the fight against antimicrobial resistance and the co-existence of AMPs on the skin of these damp-living amphibians may be of particular interest. The aim of this study is to investigate the potential synergy between aurein, maculatin and caerin AMPs.

\section{Materials and methods}

\section{Materials}

Aurein 1.1 (GLFDIIKKIAESF-NH ${ }_{2}$ ), maculatin 1.1 (GLFGVLAKVAAHVVPAIAEHF$\mathrm{NH}_{2}$ ) and caerin 1.1 (GLLSVLGSVAKHVLPHVVPVIAEHL-NH $\mathrm{N}_{2}$ ) were synthesized by solid phase peptide synthesis and HPLC purified in house (Bio21 Institute, Dr J. Karas) at a 
purity $>95 \%$. Palmitoyloleoylphosphatidylcholine (POPC), palmitoyloleoylphosphatidylethanolamine (POPE), palmitoyloleoylphosphatidylglycerol (POPG), tetraoeloylcardiolipin (TOCL) and sphingomyelin from porcine brain (SM) phospholipids were purchased from Avanti Polar Lipids (Alabaster, USA) and used without further purification. Cholesterol (Chol), 5(6)-carboxyfluorescein (CF), Triton X-100 and PD-10 columns were purchased from Sigma (St Louis, USA).

\section{Minimum inhibitory concentration assays (MIC)}

S. aureus (ATCC29213) and E. coli (MG1655) colonies were first incubated overnight on Horse Blood Agar (HBA) plates prior transferred into $10 \mathrm{~mL}$ Luria Broth media and grown for ca. $3 \mathrm{hrs}$ at $180 \mathrm{rpm}$ and $37^{\circ} \mathrm{C}$.

For determination of MIC, bacterial cells were aliquoted in 96-well microtiter plate (polypropylene; Costar Corp., Cambridge, USA) to reach a final 5 x $10^{5}$ cells (determined by McFarland standard test measured at 0.5 and OD600 at 0.125 ) and a final volume of $100 \mu \mathrm{L}$. Peptide stock solutions were made in Milli-Q water at $1 \mathrm{mM}$ for aurein, maculatin and caerin. Equimolar peptide stock solutions were made by mixing $200 \mu \mathrm{L}$ of the $1 \mathrm{mM}$ stock to reach $500 \mu \mathrm{M}$. Peptide solutions were then serially diluted into each well in triplicate to span a concentration range from $0.58 \mu \mathrm{M}$ up to $250 \mu \mathrm{M}$. Negative and positive controls were carried out by replacing the peptides with Milli-Q water and ampicillin, respectively. The plates were incubated at $37^{\circ} \mathrm{C}$ overnight. MIC was taken as the concentration at which $>90 \%$ of growth inhibition was observed.

\section{Minimum bactericidal concentration assay $(M B C)$}

A $20 \mu \mathrm{L}$ aliquot from wells with no growth were plated onto HBA plates and incubated overnight at $37^{\circ} \mathrm{C}$. Plates with no colony growth were recorded as MBC values.

\section{Circular dichroism (CD) spectroscopy}

POPC/SM/Chol (1:1:1), POPE/POPG (7:3) and POPG/CL (3:2, mol/mol) lipid systems were dissolved in chloroform/methanol (3:1 v/v) and the solvent removed by rotary evaporation to obtain homogenous lipid films. Lipid films were then redissolved in n-cyclohexane, aliquoted into microfuge tubes and the solvent removed under vacuum. Dried lipids were redissolved in $10 \mathrm{mM}$ phosphate and $1 \mathrm{mM} \mathrm{NaCl}$ buffer ( $\mathrm{pH}$ 7.4) to give $15 \mathrm{mM}$ stock solution. Lipids were then extruded 20 times through an Avanti Mini-Extruder (Avanti Polar, Alabaster, 
USA) using a $0.1 \mu \mathrm{m}$ polycarbonate filter. LUV size was confirmed by dynamic light scattering performed on a Nano Zetasizer (Malvern Instruments Ltd, UK). All peptides were prepared as $100 \mu \mathrm{M}$ solutions in $10 \mathrm{mM}$ phosphate and $1 \mathrm{mM} \mathrm{NaCl}$ buffer. For CD analysis of LUVs, samples were prepared with $20 \mu \mathrm{M}$ fixed peptide concentration and a lipid to peptide ratio of 15:1.

For CD analysis of live cells, E. coli and $S$. aureus were grown to $\mathrm{OD}_{600}=0.8 .2-4 \mathrm{~mL}$ of cell suspension was washed in $10 \mathrm{mM}$ phosphate buffer. The pelleted cells were resuspended in $10 \mathrm{mM}$ phosphate buffer to an $\mathrm{OD}_{600}$ of 1.2 and stored on ice to halt proliferation. Prior to $\mathrm{CD}$ analysis, the cells were warmed to room temperature and diluted by half in $10 \mathrm{mM}$ phosphate buffer containing $80 \mu \mathrm{M}$ peptide to give a final concentration of $40 \mu \mathrm{M}$ peptide and cells at $\mathrm{OD}_{600} 0.6$.

CD spectra were acquired on a Chirascan spectropolarimeter (Applied Photophysics Ltd, UK) between 190 and $260 \mathrm{~nm}$ using $1 \mathrm{~mm}$ pathlength quartz cell. Spectra were acquired with $1 \mathrm{~nm}$ data intervals, $0.5 \mathrm{~s}$ integration time (LUV acquisition) or $1 \mathrm{~s}$ integration time (live cell acquisition), and 3 scans accumulation. Signal was recorded as milli-degrees at $25^{\circ} \mathrm{C}$. Spectra were zeroed at $260 \mathrm{~nm}$, the lipid/cell background subtracted and then normalised to give units of mean-residue ellipticity (MRE) according to $[\theta]_{\mathrm{MRE}}=\theta /\left(\mathrm{c} \times 1 \times \mathrm{N}_{\mathrm{r}}\right)$ where $\theta$ is the recorded ellipticity in milli-degrees, $\mathrm{c}$ is the concentration of peptide in $\mathrm{dmol} \cdot \mathrm{L}^{-1}, 1$ is the pathlength in $\mathrm{cm}$, and $\mathrm{N}_{\mathrm{r}}$ is the number of residues per peptide. Note that the background was acquired in triplicate and did not show any significant intensity variation so that no mathematical manipulation was performed prior to background subtraction. Estimates of peptide secondary structure content were made through DICHROWEB (http://dichroweb.cryst.bbk.ac.uk) using CONTIN/LL method and reference data Set 7 (Lobley et al. 2002; Whitmore and Wallace 2004, 2008).

\section{Dye release assays $(D R)$}

Dye encapsulated LUVs were made similarly to the CD samples. Briefly, $0.5 \mathrm{~mL}$ of a $46 \mathrm{mM}$ carboxyfluorescein $(\mathrm{CF})$ stock solution was added to an appropriate quantity of dry lipids to reach a $20 \mathrm{mM}$ lipid concentration. Three freeze-thaw cycles were performed prior to extrusion through a $0.1 \mu \mathrm{m}$ polycarbonate filter. The external dyes were removed using a PD10 column (GE HealthCare Life Science) with a final 2.5 fold dilution in lipid concentration. The LUV concentration was fixed at $100 \mu \mathrm{M}$ in each well and the single and mixed peptide 
solutions were added at various lipid to peptide molar ratio, adjusted from 10000:1 to 5:1 depending on the lytic activity. Positive and negative controls were obtained by adding $10 \%$ Triton $\mathrm{X}$ solution (to reach a $1 \%(\mathrm{v} / \mathrm{v})$ concentration) or buffer, respectively.

The fluorescence assay was performed on a FLUOstar OPTIMA microplate Reader (BMG Labtech) using a COSTAR 96 well plate (Sigma). The excitation wavelength was set at 495 $\mathrm{nm}$ with a 485-12 $\mathrm{nm}$ filter and the bottom read emission wavelength set at $517 \mathrm{~nm}$ with a 520 filter. Two cycles of 25 reads were performed at $25^{\circ} \mathrm{C}$ with $5 \mathrm{~s}$ of orbital shaking prior to each cycle and the fluorescence intensities were then averaged. The percentage of $\mathrm{CF}$ fluorescence $(\% F)$ increase upon addition of the peptide systems was obtained by normalizing the averaged intensities (I) against negative (baseline, $\left.\mathbf{I}_{\mathbf{m i n}}\right)$ and positive $(100 \%$ release, $\mathbf{I}_{\mathbf{m a x}}$ ) controls, according to the following equation:

$$
\% F=100 * \frac{I-I_{\min }}{I_{\max }-I_{\min }}
$$

The normalized intensities were plotted against the lipid to peptide molar ratio and fitted using an empirical logistic function or sigmoid curve (Sani et al. 2014),

$$
F=F_{\max }+\frac{\left(F_{\max }-F_{\min }\right)}{\left(1+\left(\frac{x}{x_{0}}\right)^{p}\right)}
$$

where $F$ is the normalized intensity at each lipid to peptide ratio; $F_{\min }$ and $F_{\max }$ are fixed at 0 and $100 \%$, respectively; $x$ is the peptide concentration; $x_{0}$ is the concentration necessary to obtain $50 \%$ of maximal fluorescence; and $p$ is a cooperativity factor.

\section{Results}

Synergistic effect observed for MIC but not MBC

The MIC of aurein, maculatin and caerin against S. aureus and E. coli strains are quantified in Table 1. As previously reported, the three peptides showed significantly greater potency against the Gram-positive S. aureus but proved fairly inactive $(>100 \mu \mathrm{M})$ against the Gramnegative strain, E. coli (Sani et al. 2015a). Against S. aureus, maculatin exhibited the lowest MIC value $(8 \mu \mathrm{M})$ followed by caerin $(18.75 \mu \mathrm{M})$ then aurein $(37.5 \mu \mathrm{M})$.

A somewhat synergistic effect was observed against $S$. aureus when peptides were mixed at an equimolar concentration while maintaining the same total AMP concentration. The MICs obtained for aurein-caerin, aurein-maculatin and caerin-maculatin (at equimolar ratios) were 
all below or similar to the MIC obtained for the most potent peptide of the couple (Table 1) despite the concentration of each peptide in the mixture being 2 fold lower than that of the single peptide alone.

Table 1. MIC and MBC ${ }^{\mathrm{a}}$ of Australian tree frog AMPs against E. coli and S. aureus strains.

\begin{tabular}{|l|c|c|c|c|c|c|}
\hline & $\begin{array}{c}\text { aurein 1.2 } \\
(\mu \mathrm{M})\end{array}$ & $\begin{array}{c}\text { maculatin } \\
1.1(\mu \mathrm{M})\end{array}$ & $\begin{array}{c}\text { caerin } 1.1 \\
(\mu \mathrm{M})\end{array}$ & $\begin{array}{c}\text { aurein- } \\
\text { caerin }^{\mathrm{b}}(\mu \mathrm{M})\end{array}$ & $\begin{array}{c}\text { aurein- } \\
\text { maculatin }^{\mathrm{b}}( \\
\mu \mathrm{M})\end{array}$ & $\begin{array}{c}\text { caerin- } \\
\text { maculatin }^{\mathrm{b}}( \\
\mu \mathrm{M})\end{array}$
\end{tabular}

Minimum bactericidal concentration (MBC) assays, which report on the death of the bacteria rather than their growth inhibition, usually are greater in value than the MIC. As expected, all peptides and mixtures did not kill E. coli at the tested concentrations or showed a very weak effect on the Gram-negative strain (Table 1). Surprisingly, the MBC against $S$. aureus were at least four-fold greater than the MIC, with maculatin being the only significantly bactericidal peptide. All binary mixtures showed a small synergistic effect, since the MBC and MIC values were identical or lower than the most active peptide in the combined system.

\section{Secondary structures of the AMPS are independent of each other}

In buffer, all peptides except aurein displayed a CD lineshape with single minimum at 200 $\mathrm{nm}$ (spectra not shown) indicating predominantly random coil structures (Table 2), as previously reported (Fernandez et al. 2012; Fernandez et al. 2013c; Sani et al. 2012). The CD spectra of aurein, maculatin and caerin in the presence of LUV made of POPE/POPG and POPG/TOCL are shown in Figure 1. The lineshapes with minima at $222 \mathrm{~nm}$ and $209 \mathrm{~nm}$ and a maximum at $192 \mathrm{~nm}$ are typical of high helical content, as expected and reported in previous studies (Fernandez et al. 2012; Fernandez et al. 2013c; Sani et al. 2012). The deconvolution using DICHROWEB found over 50\% helical structures and about $10 \%$ of random coil structures (Table 2). The peptide equimolar mixtures did not significantly change 
the CD lineshapes and deconvolution showed similar structural content as the average of the individual peptide structures for the pair.

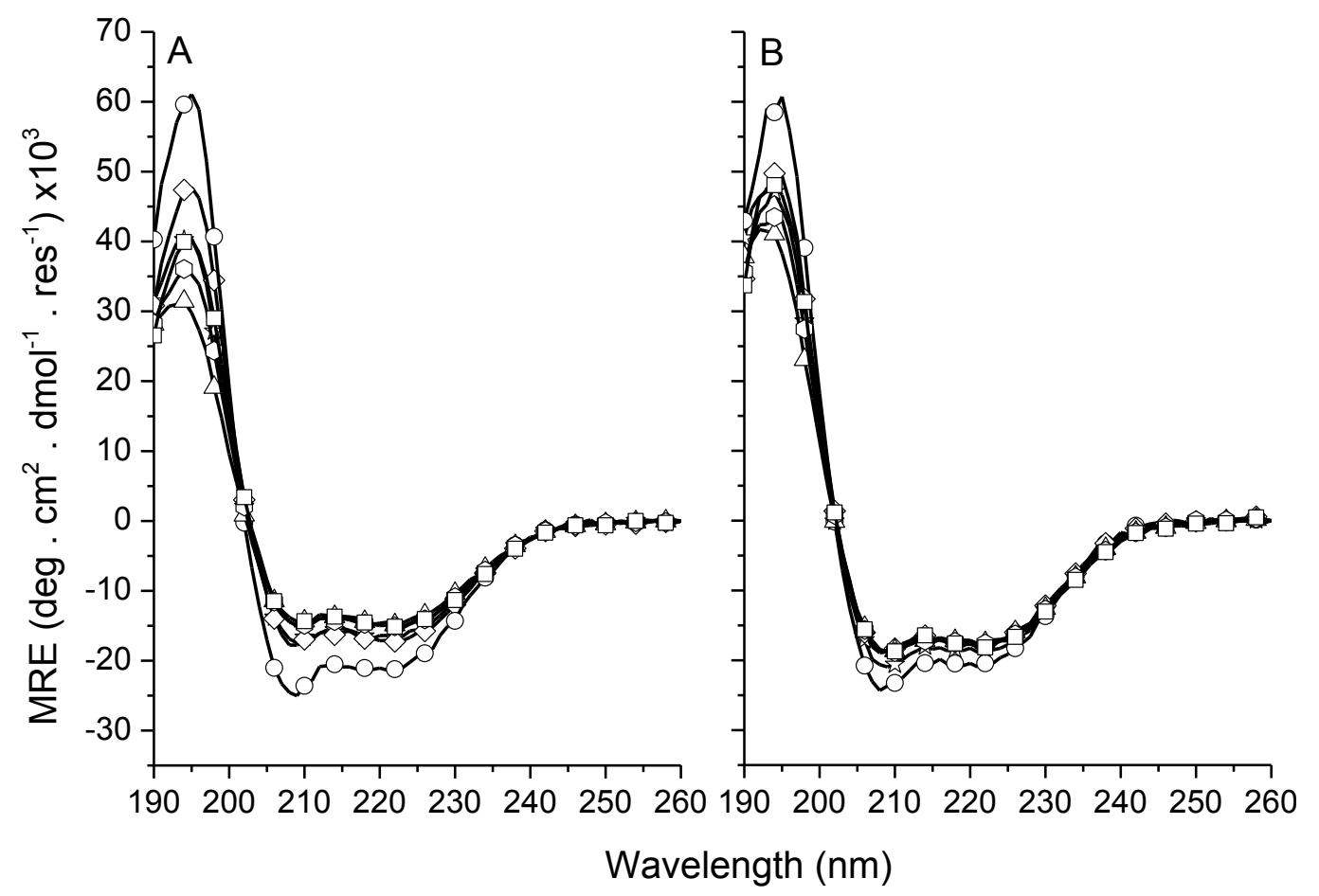

Figure 1.CD spectra of aurein 1.2 (circles), maculatin 1.1 (squares), and caerin 1.1 (triangles); and aurein-maculatin (diamonds), aurein-caerin (stars), and maculatin-caerin (hexagons) binary mixtures in the presence of LUVs made of: (A) PE/PG (7:3), and (B) PG/CL (3:2). All samples were prepared with $20 \mu \mathrm{M}$ fixed peptide concentration and a lipid to peptide molar ratio of $15: 1$. Three scans were accumulated at $25^{\circ} \mathrm{C}$.

To investigate if the peptides adopt a similar structure in the presence of $E$. coli and $S$. aureus, $\mathrm{CD}$ experiments were performed using both strains washed in phosphate buffer. The $\mathrm{CD}$ background obtained at an $\mathrm{OD}_{600}$ of 0.6 is shown in Figure 2A. Addition of the peptides to each strain produced a remarkable change in the $\mathrm{CD}$ lineshape. In the presence of $E$. coli, the CD lineshapes were similar to the lineshapes obtained in the presence of LUV, although the intensities were significantly reduced, indicating a mixture of random coil and helical structures (Table 2). However, in the presence of $S$. aureus, the CD lineshapes exhibited a single minimum at $c a 200 \mathrm{~nm}$, as observed in buffer. This change in secondary structure may reflect differences in degree of binding to the membrane (Hall et al. 2014). 


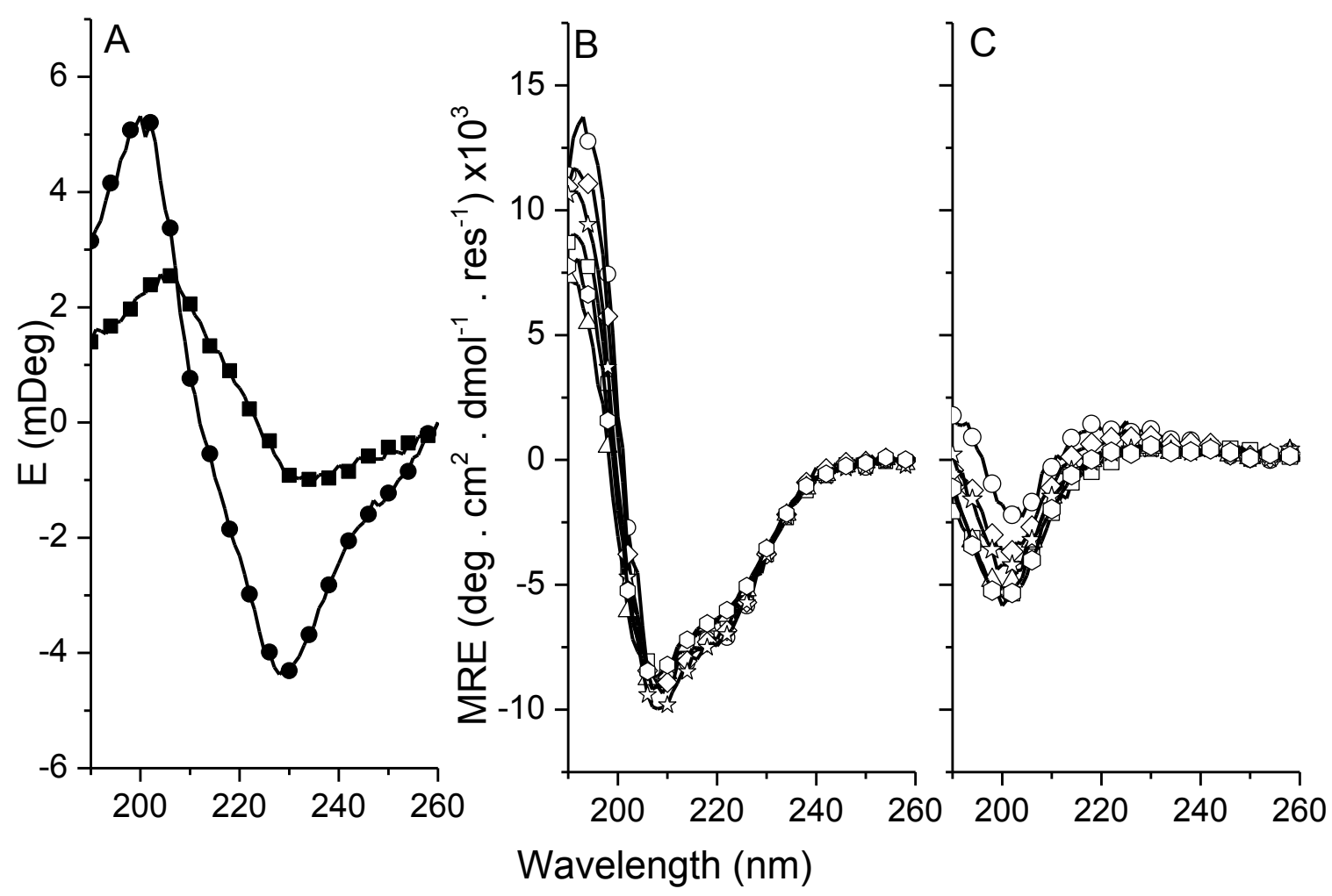

Figure 2. (A) CD spectra of live E. coli (circles) and S. aureus (squares) bacteria $\left(\mathrm{OD}_{600}\right.$ of 0.6). CD spectra of aurein 1.2 (circles), maculatin 1.1 (squares), and caerin 1.1 (triangles); and aurein-maculatin (diamonds), aurein-caerin (stars), and maculatin-caerin (hexagons) binary mixtures, in the presence of: (B) E. coli, and (C) S. aureus. All samples were prepared with $40 \mu \mathrm{M}$ fixed peptide concentration. Three scans were accumulated at $25^{\circ} \mathrm{C}$.

Table 2. Main secondary structure content ${ }^{\mathrm{a}}$ of the Australian tree frog AMPs.

\begin{tabular}{|c|c|c|c|c|c|c|}
\hline & aurein 1.2 & maculatin 1.1 & caerin 1.1 & $\begin{array}{c}\text { aurein- } \\
\text { caerin }\end{array}$ & $\begin{array}{l}\text { aurein- } \\
\text { maculatin }\end{array}$ & $\begin{array}{l}\text { caerin- } \\
\text { maculatin }\end{array}$ \\
\hline Buffer & $6(50)$ & $6(60)$ & $6(58)$ & $6(55)$ & $6(55)$ & $6(59)$ \\
\hline POPE/POPG ${ }^{\mathrm{b}}$ & $84(10)$ & $63(19)$ & $49(25)$ & $62(21)$ & $71(16)$ & $56(23)$ \\
\hline E. coli $^{\mathrm{c}}$ & $25(32)$ & $22(39)$ & $20(42)$ & $24(37)$ & $24(35)$ & $20(40)$ \\
\hline $\mathrm{POPG} \mathrm{TOCL}^{\mathrm{b}}$ & $84(12)$ & $73(15)$ & $64(20)$ & $62(19)$ & $74(15)$ & 67 (19) \\
\hline S. aureus ${ }^{\mathrm{c}}$ & $5(42)$ & $5(47)$ & $5(47)$ & $5(45)$ & $5(44)$ & $5(47)$ \\
\hline \multicolumn{7}{|c|}{$\begin{array}{l}\text { a Helical (random coil) content is given as a percentage. Deconvolution was performed with CONTIN- } \\
\text { LL using the reference data Set } 7 \text {. } \\
\text { b } \text { LUV concentration was fixed at } 300 \mu \mathrm{M} \text {. } \\
{ }^{\mathrm{c}} \text { Cell OD }_{600} \text { was fixed at } 0.6 \text {. }\end{array}$} \\
\hline
\end{tabular}


Dye release assays do not show synergistic interaction

The membrane lytic activity of the peptides was investigated by monitoring the level of carboxyfluorescein (CF) release from LUVs made of PE/PG and PG/CL (Fig. 3). Aurein was the least lytic $\left(\mathrm{LC}_{50}>8 \mu \mathrm{M}\right)$, while maculatin $\left(\mathrm{LC}_{50}<2 \mu \mathrm{M}\right)$ and caerin $\left(\mathrm{LC}_{50}<0.3 \mu \mathrm{M}\right)$ displayed significantly greater activities (Table 3). Binary mixtures produced about two-fold greater values than the most lytic peptide of the couple, which indicates no synergistic effect between the peptides for dye release from LUVs.

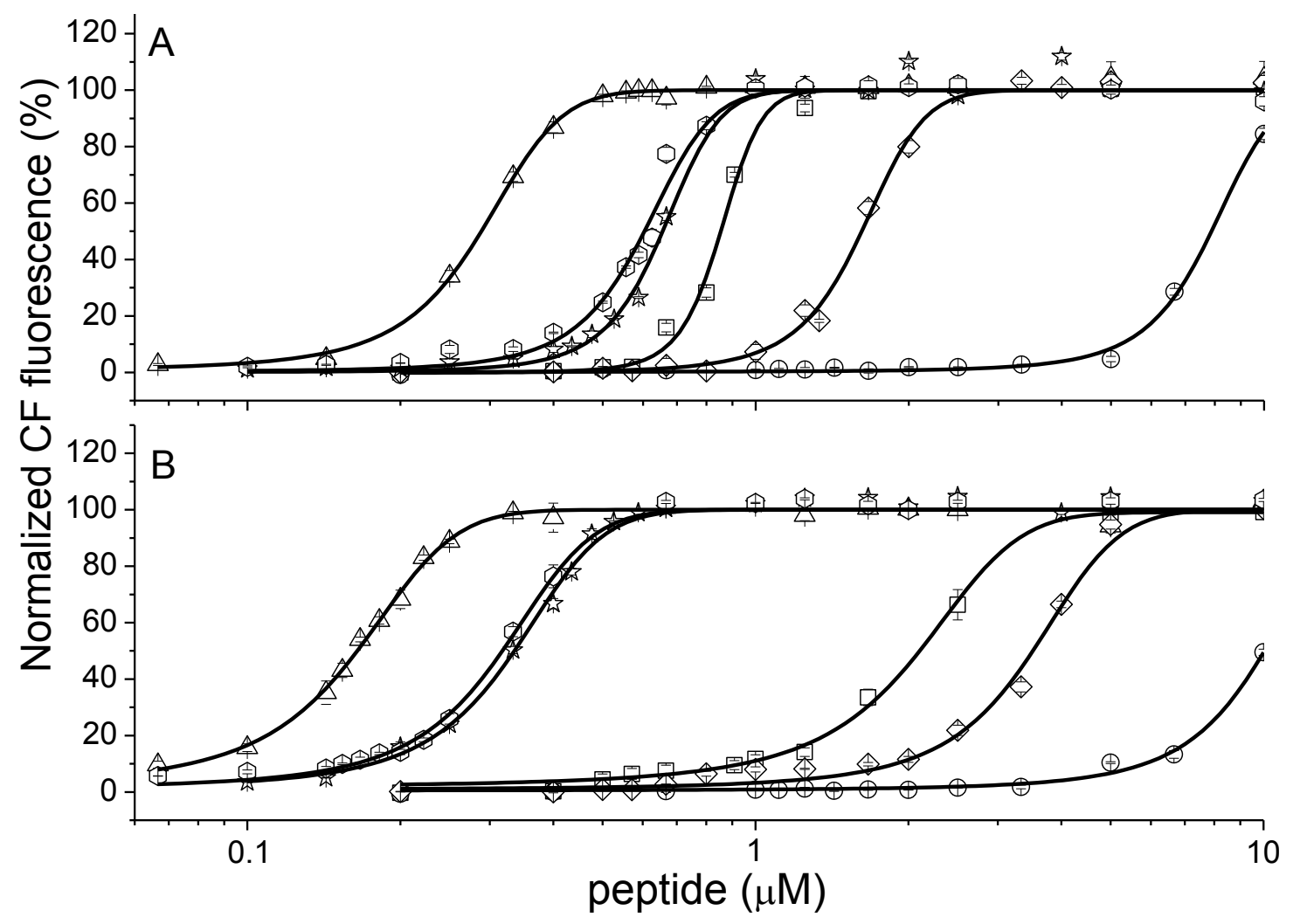

Figure 3. CF fluorescence intensity as a result of dye release from LUVs of: (A) PE/PG (7:3), and (B) PG/CL (3:2) by aurein 1.2 (circles), maculatin 1.1 (squares), and caerin 1.1 (triangles); and aurein-maculatin (diamonds), aurein-caerin (stars), and maculatin-caerin (hexagons) binary mixtures. All samples were prepared with $100 \mu \mathrm{M}$ fixed LUV concentration. Samples were made in duplicate and experiments performed at $25^{\circ} \mathrm{C}$. 
Table 3. Synergistic effects on $\mathrm{LC}_{50}{ }^{\mathrm{a}}$ for AMPs from Australian tree frogs.

\begin{tabular}{|l|c|c|c|c|c|c|}
\hline & $\begin{array}{c}\text { aurein 1.2 } \\
(\mu \mathrm{M})\end{array}$ & $\begin{array}{c}\text { maculatin 1.1 } \\
(\mu \mathrm{M})\end{array}$ & $\begin{array}{c}\text { caerin 1.1 } \\
(\mu \mathrm{M})\end{array}$ & $\begin{array}{c}\text { aurein- } \\
\text { caerin } \\
(\mu \mathrm{M})\end{array}$ & $\begin{array}{c}\text { aurein- } \\
\text { maculatin } \\
(\mu \mathrm{M})\end{array}$ & $\begin{array}{c}\text { caerin- } \\
\text { maculatin } \\
(\mu \mathrm{M})\end{array}$ \\
\hline POPE/POPG & 7.9 & 0.8 & 0.3 & 0.7 & 1.6 & 0.6 \\
\hline POPG/TOCL & 10.0 & 2.1 & 0.2 & 0.3 & 3.5 & 0.3 \\
\hline
\end{tabular}

${ }^{\mathrm{a}} \mathrm{LC}_{50}$ were obtained from fitting the fluorescence intensity as a function of increasing amount of peptide concentration using a logistic function with a typical standard deviation of less than $5 \%$. LUV concentration was fixed at $100 \mu \mathrm{M}$.

\section{Discussion}

\section{Structure-synergy relationship}

Aurein, maculatin and caerin adopted a dominant helical conformation in the presence of lipid vesicles. The peptide equimolar mixtures induced similar structural content as the average of the individual peptides within the pair (Table 2), indicating that they do not compete for the lipid interface or form greater supramolecular structures. In an helical conformation, the short 13 residue peptide, aurein, cannot span the hydrophobic core of a lipid bilayer and thus acts via a carpet mechanism that requires a high peptide concentration threshold before the lipid membrane is disrupted (Fernandez et al. 2012). Maculatin and caerin, 21 and 25 amino acids long, respectively, are able to span the hydrophobic core of a bilayer and form pores in lipid membranes (Fernandez et al. 2013c; Sani et al. 2013), which require lower peptide concentrations. The dye release assays upheld the expected difference in lytic concentration $\left(\mathrm{LC}_{50}\right)$ necessary to release entrapped $\mathrm{CF}$ dye from LUVs (Table 3), as aurein exhibited greater $\mathrm{LC}_{50}$ than maculatin or caerin. Combining peptides in pairs reduced the $\mathrm{LC}_{50}$ to about two-fold of that of the more potent peptide, indicating no obvious synergistic interactions between the carpet and pore-forming peptides or between two poreforming peptides. The study suggests that these peptides are unlikely to have significant synergistic interactions unlike, for instance, the helical magainin 2 and PGLa peptides, that were shown to adopt a stable transmembrane configuration at lower concentration when mixed at equimolar ratio (Zerweck et al. 2016). These peptides did not display a synergistic affinity for each other that would, for example, lower the critical concentration for disrupting 
lipid bilayers. Furthermore, many AMPs have been shown to adopt transient arrangements in lipid bilayers (Wang et al. 2016) and mixing peptides could either stabilize or decrease the lifetime of these assemblies. Since the helical content or the $\mathrm{LC}_{50}$ were not enhanced upon co-mixing, it is unlikely that aurein, maculatin and caerin form more stable hetero-structures. To our knowledge, synergy between carpet and pore acting peptides has not been reported. Peptide-peptide self-assembly is necessary for the lytic mechanism and, although combining peptides with different affinity for bacteria is attractive, the lytic activity of Australian tree frog aurein, maculatin and caerin peptides was not enhanced.

Most mixed pairs showed similar MICs against S. aureus as the most potent peptide of the couple, despite the concentration of the most potent peptide being half that used to determine the MIC of individual AMPs, suggestive of a small synergistic effect at a physiological level. Given that the lytic activity of AMP mixtures was equivalent to the activity of individual peptides, it is unlikely that pore formation by longer peptides (maculatin and caerin) is enhanced as a result of membrane disruption by short peptides (aurein). Thus, while the primary target of these AMPs are the lipid membrane, and disrupting its integrity can happen at much lower concentration than the reported MIC as observed for maculatin (Sani et al. 2015a), AMP interaction with a secondary intracellular target may explain the synergistic effects observed in S. aureus MIC assays. A number of AMPs have been shown to penetrate cells and interact with intracellular targets (Krizsan et al. 2014; Shah et al. 2016). One possibility is that the better membrane-disrupting peptides, maculatin and caerin, open the way for aurein, which may have a greater affinity for an intracellular target. This synergistic situation is observed when AMPs and antibiotics are mixed (Cassone and Otvos 2010; Feng et al. 2015; Nuding et al. 2014; Sanchez-Gomez et al. 2011).

\section{The role of the lipid membrane composition}

The lipid composition of biological membranes has been shown to have a critical role in the structure-function relationship of AMPs (Sani and Separovic 2016; Sani et al. 2012). The negative charge of the membrane surface can modulate both the peptide structure and the $\mathrm{LC}_{50}$ but the effects are not necessarily correlated. The CD results show that the membrane charge played a role in increasing the helical content of the cationic AMPs but helicity was not directly correlated to lytic activity since PG/CL increased $\mathrm{LC}_{50}$ but also produced the highest helical content. This is further highlighted by the surprisingly low helical content found in the presence of S. aureus (5\%), which do not correlate with the low MICs, compared to higher helical content ( $c a .25 \%)$ obtained in the presence of E. coli although all three 
peptides are less active against this strain. Conceivably, other lipids and cellular components, such as the peptidoglycan layer, may reduce peptide access to the membrane. In addition, helicity may be transient if an intracellular target is involved, further reducing the proportion of peptides detected in helical conformations. This remains a puzzling outcome, as maculatin was shown to induce dye uptake in live $S$. aureus and E. coli at similar concentrations (Sani et al. 2015a). The equimolar mixtures were not particularly sensitive to the membrane charge density, possibly due to their similar cationic charge $(+1)$ which would limit the competition in terms of electrostatic interaction. Testing mixture of peptides with greater charge difference would be interesting to see if competition occurs at the bacterial membrane interface since, during invasion, hosts usually use a wide array of AMPs.

\section{Conclusion}

AMPs show promise as alternatives to classic antibiotics, and are produced concomitantly with bacterial invasion as part of innate immune response. These peptides exist in diverse mixtures which may serve to keep bacteria in check. Since their mode of action involves peptide-peptide interaction, studying synergistic effects of peptide mixtures is of importance. Synergy between AMPs from the skin secretion of Australian tree frogs was not identified by $\mathrm{CD}$ and dye release assays using model membranes. However, MICs against S. aureus showed a synergistic effect to some extent and further characterisation using different biophysical assays or experimental conditions is required. Finally, synergy between classic antibiotics and a variety of AMPs should also be investigated, as it has been observed for other AMPs.

\section{References}

Ambroggio EE, Separovic F, Bowie J, Fidelio GD (2004) Surface behaviour and peptide-lipid interactions of the antibiotic peptides, Maculatin and Citropin. Biochimica et biophysica acta 1664:31-37

Apponyi MA, Pukala TL, Brinkworth CS, Maselli VM, Bowie JH, Tyler MJ, Booker GW, Wallace JC, Carver JA, Separovic F, Doyle J, Llewellyn LE (2004) Host-defence peptides of Australian anurans: structure, mechanism of action and evolutionary significance. Peptides 25:10351054

Blazyk J, Wiegand R, Klein J, Hammer J, Epand RM, Epand RF, Maloy WL, Kari UP (2001) A novel linear amphipathic beta-sheet cationic antimicrobial peptide with enhanced selectivity for bacterial lipids. The Journal of biological chemistry 276:27899-27906 
Cassone M, Otvos L, Jr. (2010) Synergy among antibacterial peptides and between peptides and small-molecule antibiotics. Expert review of anti-infective therapy 8:703-716

Feng $Q$, Huang $Y$, Chen M, Li G, Chen $Y$ (2015) Functional synergy of alpha-helical antimicrobial peptides and traditional antibiotics against Gram-negative and Gram-positive bacteria in vitro and in vivo. European journal of clinical microbiology \& infectious diseases : official publication of the European Society of Clinical Microbiology 34:197-204

Fernandez DI, Le Brun AP, Lee TH, Bansal P, Aguilar MI, James M, Separovic F (2013a) Structural effects of the antimicrobial peptide maculatin 1.1 on supported lipid bilayers. European biophysics journal : EBJ 42:47-59

Fernandez DI, Le Brun AP, Whitwell TC, Sani MA, James M, Separovic F (2012) The antimicrobial peptide aurein 1.2 disrupts model membranes via the carpet mechanism. Physical chemistry chemical physics : PCCP 14:15739-15751

Fernandez DI, Lee TH, Sani MA, Aguilar MI, Separovic F (2013b) Proline facilitates membrane insertion of the antimicrobial peptide maculatin 1.1 via surface indentation and subsequent lipid disordering. Biophysical journal 104:1495-1507

Fernandez DI, Sani MA, Miles AJ, Wallace BA, Separovic F (2013c) Membrane defects enhance the interaction of antimicrobial peptides, aurein 1.2 versus caerin 1.1. Biochimica et biophysica acta 1828:1863-1872

Hancock RE, Chapple DS (1999) Peptide antibiotics. Antimicrobial agents and chemotherapy 43:1317-1323

Hancock RE, Lehrer R (1998) Cationic peptides: a new source of antibiotics. Trends in biotechnology 16:82-88

Krizsan A, Volke D, Weinert S, Strater N, Knappe D, Hoffmann R (2014) Insect-derived proline-rich antimicrobial peptides kill bacteria by inhibiting bacterial protein translation at the $70 \mathrm{~S}$ ribosome. Angewandte Chemie 53:12236-12239

Laadhari M, Arnold AA, Gravel AE, Separovic F, Marcotte I (2016) Interaction of the antimicrobial peptides caerin 1.1 and aurein 1.2 with intact bacteria by $2 \mathrm{H}$ solid-state NMR. Biochimica et biophysica acta 1858:2959-2964

Lee TH, Hall KN, Aguilar MI (2016) Antimicrobial Peptide Structure and Mechanism of Action: A Focus on the Role of Membrane Structure. Current topics in medicinal chemistry 16:25-39

Lobley A, Whitmore L, Wallace BA (2002) DICHROWEB: an interactive website for the analysis of protein secondary structure from circular dichroism spectra. Bioinformatics 18:211-212

Nakatsuji T, Gallo RL (2012) Antimicrobial peptides: old molecules with new ideas. The Journal of investigative dermatology 132:887-895

Nguyen LT, Haney EF, Vogel HJ (2011) The expanding scope of antimicrobial peptide structures and their modes of action. Trends in biotechnology 29:464-472

Nuding S, Frasch T, Schaller M, Stange EF, Zabel LT (2014) Synergistic effects of antimicrobial peptides and antibiotics against Clostridium difficile. Antimicrobial agents and chemotherapy 58:5719-5725

Pasupuleti M, Schmidtchen A, Malmsten M (2012) Antimicrobial peptides: key components of the innate immune system. Critical reviews in biotechnology 32:143-171

Rozek T, Waugh RJ, Steinborner ST, Bowie JH, Tyler MJ, Wallace JC (1998) The maculatin peptides from the skin glands of the tree frog Litoria genimaculata: a comparison of the structures and antibacterial activities of maculatin 1.1 and caerin 1.1. Journal of peptide science : an official publication of the European Peptide Society 4:111-115

Salditt T, Li C, Spaar A (2006) Structure of antimicrobial peptides and lipid membranes probed by interface-sensitive X-ray scattering. Biochimica et biophysica acta 1758:1483-1498

Sanchez-Gomez S, Japelj B, Jerala R, Moriyon I, Fernandez Alonso M, Leiva J, Blondelle SE, Andra J, Brandenburg K, Lohner K, Martinez de Tejada G (2011) Structural features governing the activity of lactoferricin-derived peptides that act in synergy with antibiotics against 
Pseudomonas aeruginosa in vitro and in vivo. Antimicrobial agents and chemotherapy $55: 218-228$

Sani MA, Gagne E, Gehman JD, Whitwell TC, Separovic F (2014) Dye-release assay for investigation of antimicrobial peptide activity in a competitive lipid environment. European biophysics journal : EBJ 43:445-450

Sani MA, Henriques ST, Weber D, Separovic F (2015a) Bacteria May Cope Differently from Similar Membrane Damage Caused by the Australian Tree Frog Antimicrobial Peptide Maculatin 1.1. The Journal of biological chemistry 290:19853-19862

Sani MA, Lee TH, Aguilar MI, Separovic F (2015b) Proline-15 creates an amphipathic wedge in maculatin 1.1 peptides that drives lipid membrane disruption. Biochimica et biophysica acta 1848:2277-2289

Sani MA, Separovic F (2016) How Membrane-Active Peptides Get into Lipid Membranes. Accounts of chemical research 49:1130-1138

Sani MA, Whitwell TC, Gehman JD, Robins-Browne RM, Pantarat N, Attard TJ, Reynolds EC, O'BrienSimpson NM, Separovic F (2013) Maculatin 1.1 disrupts Staphylococcus aureus lipid membranes via a pore mechanism. Antimicrobial agents and chemotherapy 57:3593-3600

Sani MA, Whitwell TC, Separovic F (2012) Lipid composition regulates the conformation and insertion of the antimicrobial peptide maculatin 1.1. Biochimica et biophysica acta 1818:205211

Shah P, Hsiao FS, Ho YH, Chen CS (2016) The proteome targets of intracellular targeting antimicrobial peptides. Proteomics 16:1225-1237

Tachi T, Epand RF, Epand RM, Matsuzaki K (2002) Position-dependent hydrophobicity of the antimicrobial magainin peptide affects the mode of peptide-lipid interactions and selective toxicity. Biochemistry 41:10723-10731

Wang Y, Chen $\mathrm{CH}, \mathrm{Hu}$ D, Ulmschneider MB, Ulmschneider JP (2016) Spontaneous formation of structurally diverse membrane channel architectures from a single antimicrobial peptide. Nature communications 7:13535

Whitmore L, Wallace BA (2004) DICHROWEB, an online server for protein secondary structure analyses from circular dichroism spectroscopic data. Nucleic acids research 32:W668-673

Whitmore L, Wallace BA (2008) Protein secondary structure analyses from circular dichroism spectroscopy: methods and reference databases. Biopolymers 89:392-400

Zerweck J, Strandberg E, Burck J, Reichert J, Wadhwani P, Kukharenko O, Ulrich AS (2016) Homo- and heteromeric interaction strengths of the synergistic antimicrobial peptides PGLa and magainin 2 in membranes. European biophysics journal : EBJ 45:535-547 


\section{University Library}

\section{- M M N E R VA A gateway to Melbourne's research publications}

Minerva Access is the Institutional Repository of The University of Melbourne

Author/s:

Sani, M-A;Carne, S;Overall, SA;Poulhazan, A;Separovic, F

Title:

One pathogen two stones: are Australian tree frog antimicrobial peptides synergistic against human pathogens?

Date:

2017-10-01

Citation:

Sani, M. -A., Carne, S., Overall, S. A., Poulhazan, A. \& Separovic, F. (2017). One pathogen two stones: are Australian tree frog antimicrobial peptides synergistic against human pathogens?. EUROPEAN BIOPHYSICS JOURNAL WITH BIOPHYSICS LETTERS, 46 (7), pp.639-646. https://doi.org/10.1007/s00249-017-1215-9.

Persistent Link:

http://hdl.handle.net/11343/282840 